Check for updates

Cite this: RSC Adv., 2017, 7, 26420

\title{
Synthesis and properties of fluorinated polyimides with multi-bulky pendant groups
}

\author{
Chenyi Wang, (DD *ab Shijie Cao, ${ }^{\text {ab }}$ Wentao Chen, ${ }^{\text {ab }}$ Chang Xu, ${ }^{\text {ab }}$ Xiaoyan Zhao, ${ }^{\text {ab }}$ \\ Jian Li and Qiang Ren ${ }^{\mathrm{b}}$
}

A new aromatic diamine monomer, 2,2'-bis[3,5-di(4-trifluoromethylphenyl)-4-(4-aminophenoxy)phenyl] sulfone, containing four pendant trifluoromethylphenyl group substituents was successfully synthesized via a three-step reaction from readily available reagents. A new series of fluorinated polyimides with multi-bulky pendant groups was prepared from the diamine monomer with three commercially available aromatic tetracarboxylic dianhydrides using one-step high-temperature polycondensation. The incorporation of multi-bulky pendant fluorinated groups and large non-coplanar structures brought about a great improvement in their properties. The resulting polyimides had excellent solubility and the maximum solubility even reached 20 wt\% in $\mathrm{NMP}, \mathrm{CHCl}_{3}$, and $\mathrm{THF}$ at room temperature. Their film displayed a light color and high optical transparency with the cut-off wavelengths ranging from 327 to $343 \mathrm{~nm}$. They also possessed intrinsically low dielectric constant values of $2.69-2.85$ (at $1 \mathrm{MHz}$ ) and low water absorption (0.59-0.68\%). Moreover, these polyimides showed high glass transition temperatures $\left(259-281^{\circ} \mathrm{C}\right.$ ) and excellent thermal stability with $5 \%$ weight loss at temperatures over the range of 551$561{ }^{\circ} \mathrm{C}$ and $515-520{ }^{\circ} \mathrm{C}$ under nitrogen and air atmospheres, respectively. Compared to some trifluoromethyl-substituted polyimides, these polyimides with multi-bulky pendant groups possessed better solubility and lower cut-off wavelength and dielectric constants.

Received 7th February 2017 Accepted 23rd April 2017

DOI: $10.1039 / c 7 r a 01568 b$

rsc.li/rsc-advances properties. ${ }^{8}$ Incorporation of bulky pendant groups along the polymer backbone is regarded as one of the effective strategies. ${ }^{9-15}$ For example, Chern reported a series of polyimides with di-tert-butyl pendant groups in the repeating unit, prepared by one-step polycondensation. ${ }^{9}$ These polyimides had good solubility in some aprotic solvents and exhibited low dielectric constants with the values of 2.78-3.02 at $1 \mathrm{MHz}$. Swage prepared a series of triptycene polyimides based on 2,6-diaminotriptycene derivatives and five- and six-membered ring anhydrides. ${ }^{13}$ These completely aromatic polyimides were soluble in some organic solvents and their films possessed high surface areas and low refractive indices and dielectric constants. However, the incorporation of these bulky alkyl or alicyclic groups generally degrades the thermal stabilities of the obtained polyimides. In addition, the preparation of polyimides with bulky pendant alkyl groups is usually very complicated, and the key issue is how to design and develop new suitable monomers.

In recent years, significant attention has been focused on fluorinated polyimides, especially on trifluoromethylsubstituted polyimides. ${ }^{16}$ These fluorinated polyimides display reduced dielectric property as well as improved solubility and optical transparency as compared to their non-fluorinated counterparts. ${ }^{17-24}$ The pendant trifluoromethyl groups played a key role in improving the performance of polyimides because of their bulky free volume, low polarizability, and high

\footnotetext{
ajiangsu Key Laboratory of Environmentally Friendly Polymeric Materials, Changzhou University, State Key Laboratory for Modification of Chemical Fibers and Polymer Materials, Donghua University, China.E-mail: wangcy@cczu.edu.cn; zhaoxiaoyan@ cczu.edu.cn

${ }^{b}$ School of Materials Science and Engineering, Changzhou University, Changzhou 213164, China
} 
hydrophobicity. They are believed to be a new generation of microelectronic and optoelectronic materials and have important application value. However, some of these fluorinated polyimides derived from BPDA still showed a limited solubility and were nearly insoluble in all the tested solvents. ${ }^{17-20}$ From the point of view of structural design, polyimides will possess better solubility and lower dielectric properties with the introduction of more pendant trifluoromethyl groups or more bulky fluorinated groups. Generally, it is convenient to obtain fluorinated polyimides with one or two trifluoromethyl groups in the repeating unit; however, it is difficult to obtain polyimides with multiple trifluoromethyl groups or bulky fluorinated groups due to difficulty in the preparation of fluorinated monomers.

As part of the efforts made to obtain highly soluble PIs with eminent dielectric and optical properties for microelectronic and photoelectric applications, the present study reports a new aromatic diamine and a series of fluorinated polyimides containing four pendant trifluoromethylphenyl groups in the repeating unit prepared via one-step high-temperature polycondensation. These polymers are expected to show excellent solubility and dielectric and optical properties due to the incorporation of multi-bulky fluorinated pendant groups. To the best of our knowledge, there are very few reports about fluorinated polyimides with multi-bulky pendant fluorinated groups in the repeating unit. The structures, solubility, dielectric constant, optical transparency, and thermal/mechanical properties of the obtained polyimides were investigated and discussed in detail.

\section{Experimental}

\section{Materials and measurements}

4,4'-Difluorodiphenyl sulfone (DFDPS), $N$-bromosuccinimide (NBS), and 4-aminophenol were purchased from TCI company and used as received. 4-(Trifluoromethyl)benzeneboronic acid was purchased from Soochiral Chemical Co. and used as received. Tetrakis(triphenylphosphine) palladium (0) was purchased from Shanxi Kaida Chemical Co. and used as received. Aromatic tetracarboxylic dianhydrides such as $3,3^{\prime}, 4,4^{\prime}$-biphenyltetracarboxylic dianhydride (BPDA or 4a), $3,3^{\prime}, 4,4^{\prime}$-benzophenonetetracarboxylic dianhydride (BTDA or $4 \mathrm{~b}$ ), and 4,4'-oxydiphthalic dianhydride (ODPA or 4c) were purchased from TCI company and further purified by recrystallization from acetic anhydride. Commercially available $\mathrm{N}$ methyl-2-pyrrolidinone (NMP), m-cresol, $N, N$-dimethylacetamide (DMAc), $N, N$-dimethylformamide (DMF), dimethyl sulfoxide (DMSO), tetrahydrofuran (THF), and other reagents were used as received.

NMR spectra were obtained using a Bruker AV400 instrument with dimethyl sulfoxide- $d_{6}$ (DMSO- $d_{6}$ ) or $\mathrm{CDCl}_{3}$ as the solvent and tetramethylsilane (TMS) as the internal standard. FTIR spectra were obtained using a Nicolet NEXUS 670 spectrometer. Gel permeation chromatography (GPC) on soluble polymers was performed using a Waters 1515 system equipped with a triple detector array and a packing column (StyragelHT4 WAT044210, $7.8 \times 300 \mathrm{~mm}$ ) using tetrahydrofuran (THF) as an eluent at $25{ }^{\circ} \mathrm{C}$ and the flow rate of $1 \mathrm{~mL} \mathrm{~min}{ }^{-1}$. The glass transition temperatures $T_{\mathrm{g}}$ of the membranes were characterized using differential scanning calorimetry (DSC, PE diamond DSC instrument). The samples were tested for two consecutive scans at the heating rate of $20{ }^{\circ} \mathrm{C} \mathrm{min}^{-1}$. The first cycle of ramping and cooling was carried out to eliminate any thermal history of the samples. The $T_{\mathrm{g}}$ of each sample was obtained based on the mid-point transition temperature of the second heating curve. Thermogravimetric analysis (TGA) of the polymer samples was performed using a Netzsch TG 209F1 instrument at the heating rate of $20{ }^{\circ} \mathrm{C} \min ^{-1}$ under a nitrogen and air atmosphere. The tensile properties were obtained using an Instron 5565 Tensile Apparatus with a $5 \mathrm{~kg}$ load cell at the crosshead speed of $5 \mathrm{~mm} \mathrm{~min}{ }^{-1}$ on the strips approximately 60$80 \mu \mathrm{m}$ thick and $0.5 \mathrm{~cm}$ wide with a $2 \mathrm{~cm}$ gauge length. An average of at least three individual determinations was used. Ultraviolet-visible (UV-vis) spectra of the polymer films were obtained using a PerkinElmer Lambda35 UV-vis spectrophotometer at room temperature. The equilibrium water absorption was determined by measuring the weight changes in the vacuum-dried film specimens before and after immersion in deionized water at $25^{\circ} \mathrm{C}$ for 3 days. The dielectric property of the polymer films was measured by the parallel-plate capacitor method using a TH2826 LCR Meter. Gold electrodes were vacuum-deposited on both surfaces of the dried films before testing, and the experiments were performed in a dry chamber.

Synthesis of 2,2'-bis(3,5-dibromo-4-fluorophenyl)sulfone (1). 2,2'-Bis(3,5-dibromo-4-fluorophenyl)sulfone (mp: $180-182{ }^{\circ} \mathrm{C}$ ) was conveniently synthesized according to a procedure reported in our previous study. ${ }^{25}$

Synthesis of 2,2'-bis[3,5-di(4-trifluoromethylphenyl)-4fluorophenyl]sulfone (2). Herein, $22.79 \mathrm{~g}$ (0.04 mol) of 2,2'bis(3,5-dibromo-4-fluorophenyl)sulfone and $31.14 \mathrm{~g}(0.164 \mathrm{~mol})$ of 4-(trifluoromethyl)benzeneboronic acid were dissolved in 500 $\mathrm{mL}$ of toluene/ethylene glycol dimethyl ether $(1: 1, \mathrm{v} / \mathrm{v})$ in a $2 \mathrm{~L}$ three-necked round-bottom flask equipped with a reflux condenser, mechanical stirrer, and nitrogen inlet at $50{ }^{\circ} \mathrm{C}$. After this, $200 \mathrm{~mL}$ of $15 \mathrm{wt} \%$ aqueous sodium carbonate solution and $3.7 \mathrm{~g}$ of $9 \%$ tetrakis(triphenylphosphine) palladium (0) were carefully added to the solution, and then, the reaction mixture was heated at $110^{\circ} \mathrm{C}$ for $10 \mathrm{~h}$. Afterward, toluene was evaporated to obtain a suspended solution, and the precipitate was obtained by filtration. The crude product was recrystallized from toluene to afford pure white crystalline 2,2'-bis[3,5-di(4trifluoromethylphenyl)-4-fluorophenyl]sulfone. Yield: $80 \%$, mp: $315-316^{\circ} \mathrm{C}$.

FT-IR (KBr) $\nu / \mathrm{cm}^{-1}: 2926,1329,1168,1120 .{ }^{1} \mathrm{H} \mathrm{NMR}\left(\mathrm{CDCl}_{3}\right.$, $400 \mathrm{MHz}) \delta: 8.07(\mathrm{~d}, J=6.3 \mathrm{~Hz}, 4 \mathrm{H}), 7.76(\mathrm{~d}, J=8.3 \mathrm{~Hz}, 8 \mathrm{H}), 7.67$ $(\mathrm{d}, J=8.0 \mathrm{~Hz}, 8 \mathrm{H})$.

Synthesis of 2,2'-bis[3,5-di(4-trifluoromethylphenyl)-4-(4aminophenoxy)-phenyl]-sulfone (3). Herein, $24.92 \mathrm{~g}(0.03 \mathrm{~mol})$ of intermediate compound $2,6.76 \mathrm{~g}(0.062 \mathrm{~mol})$ of 4 -aminophenol, $8.57 \mathrm{~g}(0.062 \mathrm{~mol})$ of potassium carbonate, and $70 \mathrm{~mL}$ of DMF were added in a $250 \mathrm{~mL}$ four-necked round-bottom flask equipped with a reflux condenser, mechanical stirrer, and nitrogen inlet. The reaction mixture was stirred under a nitrogen atmosphere at $110{ }^{\circ} \mathrm{C}$ for $10 \mathrm{~h}$. Then, the solution was poured in water to precipitate the pale-white solid, which was 
filtered and repeatedly washed with water. The crude product was further purified using a silica gel column with a $4: 1(\mathrm{v} / \mathrm{v})$ mixture of dichloromethane and petroleum ether $\left(60-90{ }^{\circ} \mathrm{C}\right)$ as the eluent. Yield: $61 \%$; mp: $261-263{ }^{\circ} \mathrm{C}$ by DSC at the scan rate of $10{ }^{\circ} \mathrm{C} \mathrm{min}{ }^{-1}$.

FT-IR (KBr) $\nu / \mathrm{cm}^{-1}:$ 3416, 3365, 2923, 1617, 1508, 1326, 1224, 1166, 1127, 1104. ${ }^{1} \mathrm{H} \mathrm{NMR}\left(\mathrm{CDCl}_{3}, 400 \mathrm{MHz}\right) \delta: 8.04(\mathrm{~s}, 4 \mathrm{H}), 7.57$ $(\mathrm{m}, 16 \mathrm{H}), 6.27(\mathrm{~d}, J=6.8 \mathrm{~Hz}, 4 \mathrm{H}), 6.20(\mathrm{~d}, J=6.8 \mathrm{~Hz}, 4 \mathrm{H}), 3.32(\mathrm{~s}$, $4 \mathrm{H}) .{ }^{13} \mathrm{C}-\mathrm{NMR}\left(100 \mathrm{MHz}, \mathrm{CDCl}_{3}, \mathrm{ppm}\right): 154.5,150.0,141.4$, 139.5, 138.1, 136.9, 130.5, $130.2\left(\left(\mathrm{q},{ }^{2} J_{\mathrm{C}-\mathrm{F}}=25.8\right)\right), 129.5,125.3$, $123.8\left(\mathrm{q},{ }^{1} J_{\mathrm{C}-\mathrm{F}}=218.8\right), 116.7,115.8$. Elemental analysis: calcd for $\mathrm{C}_{52} \mathrm{H}_{32} \mathrm{~F}_{12} \mathrm{~N}_{2} \mathrm{O}_{4} \mathrm{~S}$ (1008.87): C 61.91\%, H 3.20\%, N 2.78\%. Found: C $62.00 \%$, H $3.28 \%$, N $2.74 \%$.

Synthesis of fluorinated polyimides $(5 a-c)$. Polymerization was carried out by treating the synthesized diamine 3 with three structurally different aromatic dianhydride monomers. The general procedure for the polymer preparation was as follows. Diamine 3 (1.5 $\mathrm{mmol})$ and dianhydride monomer $4(1.5 \mathrm{mmol})$ were first dissolved in $12 \mathrm{~mL}$ of $\mathrm{m}$-cresol in a completely dried $50 \mathrm{~mL}$ three-necked round-bottom flask equipped with a mechanical stirrer, a condenser, and a nitrogen inlet/outlet. Under mechanical stirring at room temperature for $30 \mathrm{~min}$, isoquinoline ( $c a .4$ drops) was added. Then, the reaction solution was heated at $190{ }^{\circ} \mathrm{C}$ for about $12-20 \mathrm{~h}$. Water formed during imidization was continuously removed using a stream of nitrogen. At the end of the reaction, the highly viscous polymer solution was cooled and precipitated using $300 \mathrm{~mL}$ ethanol. The resulting fiber-like precipitate was obtained by filtration, washing with hot water several times, and drying overnight at $120{ }^{\circ} \mathrm{C}$ under vacuum.

PI 5a. FT-IR (film) $\nu / \mathrm{cm}^{-1}:$ 3061, 1778, 1733, 1616, 1509, 1385, 1320, 1230, 1176, 1130, 1051, 735. ${ }^{1} \mathrm{H} \mathrm{NMR}\left(\mathrm{CDCl}_{3}, 400 \mathrm{MHz}\right) \delta$ : $8.12(\mathrm{~m}, 6 \mathrm{H}), 8.01(\mathrm{~s}, 4 \mathrm{H}), 7.62(\mathrm{~m}, 16 \mathrm{H}), 7.10(\mathrm{~d}, J=8.0 \mathrm{~Hz}, 4 \mathrm{H})$, $6.56(\mathrm{~d}, J=8.0 \mathrm{~Hz}, 4 \mathrm{H})$. Elemental analysis: calcd for $\mathrm{C}_{68} \mathrm{H}_{34} \mathrm{~F}_{12} \mathrm{~N}_{2} \mathrm{O}_{8} \mathrm{~S}$ (1267.05): C 64.46\%, H 2.70\%, N 2.21\%. Found: C $63.80 \%$, H $2.68 \%$, N $2.18 \%$.

PI 5b. FT-IR (film) $\nu / \mathrm{cm}^{-1}:$ 3061, 1778, 1733, 1615, 1508, 1383, 1321, 1231, 1159, 1123, 1050, 730. ${ }^{1} \mathrm{H} \mathrm{NMR}\left(\mathrm{CDCl}_{3}, 400 \mathrm{MHz}\right) \delta$ : $8.19(\mathrm{~m}, 4 \mathrm{H}), 8.12(\mathrm{~s}, 4 \mathrm{H}), 8.06(\mathrm{~d}, J=8.0 \mathrm{~Hz}, 2 \mathrm{H}), 7.61(\mathrm{~m}, 16 \mathrm{H})$, $7.08(\mathrm{~d}, J=8.0 \mathrm{~Hz}, 4 \mathrm{H}), 6.56(\mathrm{~d}, J=8.0 \mathrm{~Hz}, 4 \mathrm{H})$. Elemental analysis: calcd for $\mathrm{C}_{69} \mathrm{H}_{34} \mathrm{~F}_{12} \mathrm{~N}_{2} \mathrm{O}_{9} \mathrm{~S}$ (1295.06): $\mathrm{C} 63.99 \%, \mathrm{H}$ $2.65 \%$, N 2.16\%. Found: C 63.57\%, H 2.58\%, N 2.11\%.

PI 5c. FT-IR (film) $\nu / \mathrm{cm}^{-1}: 3070,1778,1733,1608,1509,1383$, 1320, 1275, 1240, 1168, 1123, 1050, 735. ${ }^{1} \mathrm{H} \mathrm{NMR}\left(\mathrm{CDCl}_{3}, 400\right.$ MHz) $\delta: 8.11(\mathrm{~m}, 4 \mathrm{H}), 7.92(\mathrm{~d}, J=8.0 \mathrm{~Hz}, 2 \mathrm{H}), 7.60(\mathrm{~m}, 16 \mathrm{H}), 7.45$ $(\mathrm{s}, 2 \mathrm{H}), 7.40(\mathrm{~d}, J=8.0 \mathrm{~Hz}, 2 \mathrm{H}), 7.05(\mathrm{~d}, J=8.0 \mathrm{~Hz}, 4 \mathrm{H}), 6.54(\mathrm{~d}, J$ $=8.0 \mathrm{~Hz}, 4 \mathrm{H})$. Elemental analysis: calcd for $\mathrm{C}_{68} \mathrm{H}_{34} \mathrm{~F}_{12} \mathrm{~N}_{2} \mathrm{O}_{9} \mathrm{~S}$ (1283.05): C 63.66\%, H 2.67\%, N 2.18\%. Found: C $63.20 \%, \mathrm{H}$ $2.58 \%$, N $2.13 \%$.

\section{Results and discussion}

\section{Synthesis of the monomer}

As depicted in Scheme 1, the new diamine monomer 2,2'-bis [3,5-di(4-trifluoromethylphenyl)-4-(4-aminophenoxy)phenyl]sulfone (3) was synthesized by a three-step reaction using $4,4^{\prime}$ difluorodiphenyl sulfone and NBS as the starting materials.
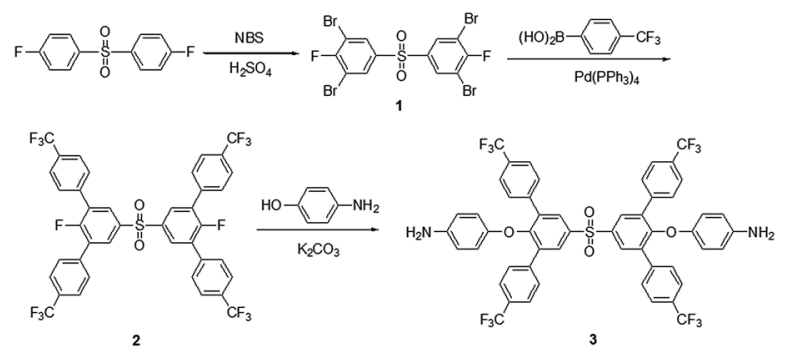

Scheme 1 Synthesis of the aromatic diamine 3.

First, the precursor 1 was synthesized via a free-radical substitution reaction using concentrated sulfuric acid as the solvent and catalyst according to a reported procedure. Following this, the intermediate compound 2 was produced by a Suzuki coupling reaction of 1 with 4-(trifluoromethyl)benzeneboronic acid. Finally, the diamine monomer 3 was obtained via a nucleophilic substitution reaction of 2 and 4-aminophenol in the presence of potassium carbonate in DMF. The crude diamine 3 was purified using a silica gel column and directly used for the synthesis of PIs. The structure of diamine 3 was confirmed by FTIR and NMR spectroscopies and elemental analysis. In the FTIR spectrum, diamine 3 exhibited the characteristic $\mathrm{N}-\mathrm{H}$ stretching bands at $3300-3500 \mathrm{~cm}^{-1}$, together with some strong absorption bands in the region of 1100-1300 $\mathrm{cm}^{-1}$ because of the $\mathrm{C}-\mathrm{O}$ and $\mathrm{C}-\mathrm{F}$ stretching (Fig. 1a). The characteristic sulfone groups and phenyl rings ( $\mathrm{Ar}-\mathrm{H}$ and $\mathrm{C}-\mathrm{C}$ ) stretching peaks appeared at 1326, 2923, 1617, and $1508 \mathrm{~cm}^{-1}$. Fig. 2a and b illustrate the ${ }^{1} \mathrm{H}$ NMR and ${ }^{13} \mathrm{C}$ NMR spectra of diamine monomer 3 in $\mathrm{CDCl}_{3}$, respectively. Assignments of each proton and carbon were assisted by the two-dimensional NMR spectra, as shown in Fig. 3, and these spectra agreed well with the proposed molecular structure of 3 . In the ${ }^{1} \mathrm{H}$ NMR spectrum, the primary aromatic amine protons appeared at $3.32 \mathrm{ppm}$ and the protons in the aromatic rings $\left(H_{\mathrm{a}}\right.$ to $\left.H_{\mathrm{e}}\right)$ appeared at 6.20-8.04 ppm. $H_{\mathrm{a}}$ exhibited obvious deshielding due to the strong electron-withdrawing effect of the sulfone group and appeared at $8.04 \mathrm{ppm}$. In the ${ }^{13} \mathrm{C}$ NMR spectrum, all

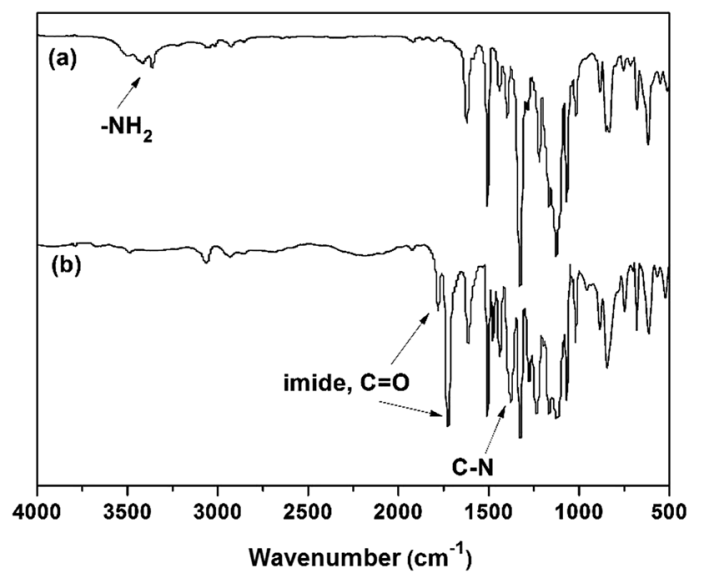

Fig. 1 (a) FTIR spectrum of diamine 3 and (b) FTIR spectrum of PI $5 a$. 

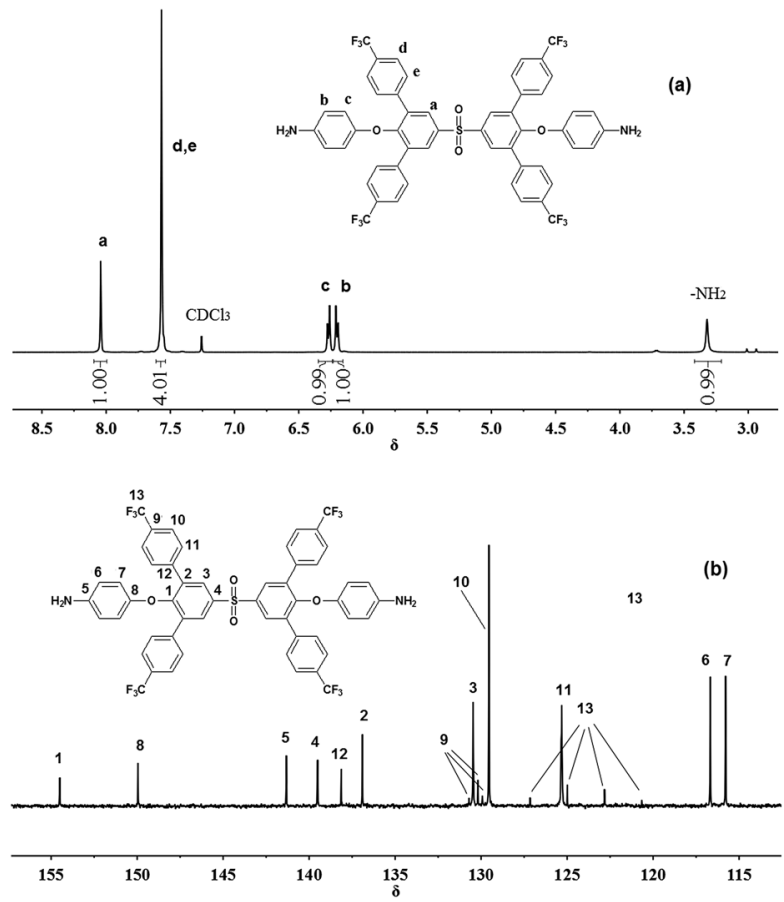

Fig. 2 (a) ${ }^{1} \mathrm{H}$ NMR spectrum of diamine 3 and (b) ${ }^{13} \mathrm{C}$ NMR spectrum of diamine 3 .

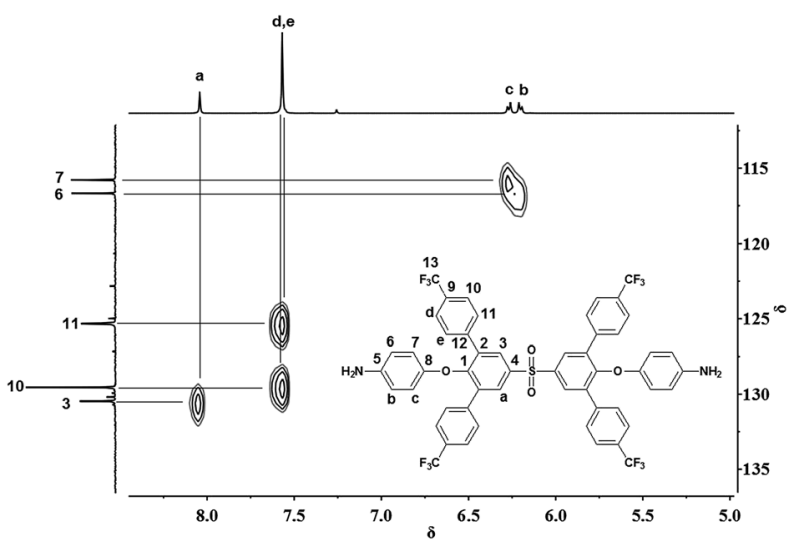

Fig. $3 \mathrm{C}^{13}-\mathrm{H}^{1} \mathrm{COSY}$ spectrum of diamine monomer 3 in $\mathrm{CDCl}_{3}$.

the carbon-13 atoms resonated in the region of 115-155 ppm, and four quartets were observed because of the heteronuclear ${ }^{13} \mathrm{C}-{ }^{19} \mathrm{~F}$ coupling. The large quartets centered at about 123.8 $\left(\mathrm{C}^{13}\right)$ ppm are peculiar to $\mathrm{CF}_{3}$ carbons, and the one-bond $\mathrm{C}-\mathrm{F}$ coupling constant in these cases is about $218.8 \mathrm{~Hz}$. The $\mathrm{CF}_{3^{-}}$ attached carbons $\mathrm{C}^{9}$ also show clear quartets centered at 130.2 ppm, with a small coupling constant of about $25.8 \mathrm{~Hz}$ due to two-bond C-F coupling. Therefore, all the spectroscopic data provided clear evidence of the proposed structure of the target diamine monomer 3. Moreover, the elemental analysis values of diamine 3 were also in good agreement with the calculated values.

Due to the introduction of multi-bulky pendant groups (trifluoromethylphenyl groups) at the ortho-position of the ether linkage of phenyl rings in diamine 3 , the diamine monomer would possess a kink non-coplanar structure to maintain a minimum energy of conformation. As shown in the molecular model of diamine 3 (Fig. 4), the aromatic phenyl rings connected with the ether bonds displayed a large dihedral angle. Thus, the structure of diamine 3 was designed to achieve several desirable properties, such as good solubility, low dielectric constant, and high optical transparency, of the obtained PIs.

\section{Synthesis of polymers}

The fluorinated PIs 5a-c could be prepared from diamine 3 and three available aromatic dianhydrides 4a-c (BPDA, BTDA, and ODPA) by one-step solution polycondensation, as shown in Scheme 2. The polymerization was carried out by treating stoichiometric amounts of diamine monomer 3 with aromatic dianhydrides at the concentration of about $10-20 \mathrm{wt} \%$ solids in $\mathrm{m}$-cresol. In spite of the presence of multi-bulky trifluoromethylphenyl substituents, the diamine 3 was still sufficiently reactive to provide fibrous polymer resins when it was allowed to polymerize for about 12-20 h. The polymers were obtained in almost quantitative yields, and the inherent viscosities were in the range of $0.79-0.96 \mathrm{dL} \mathrm{g}^{-1}$ in NMP solution, as summarized in Table 1. According to the gel permeation chromatography (GPC) measurement results (Table 1), the $M_{\mathrm{n}}$ and polydispersities $\left(M_{\mathrm{w}} / M_{\mathrm{n}}\right)$ values of the PIs dissolved in THF were in the range of $865000-126700$ and 1.55-1.69, respectively. The molecular weight of PI $5 \mathrm{~b}$ exhibited a slight decrease compared to that of PI $5 \mathrm{a}$ and $5 \mathrm{c}$, which was mainly attributed to the activity of the dianhydride monomers.

The chemical structures of the polyimides were characterized by FTIR and ${ }^{1} \mathrm{H}$ NMR analysis. All the polymers exhibited characteristic imide group absorptions around 1778 and 1733 $\mathrm{cm}^{-1}$ (typical of imide carbonyl asymmetrical and symmetrical stretch), 1385 (C-N stretch), and 1051 and $735 \mathrm{~cm}^{-1}$ (imide ring deformation), together with some strong absorption bands in the region of $1100-1300 \mathrm{~cm}^{-1}$ because of the $\mathrm{C}-\mathrm{O}$ and $\mathrm{C}-\mathrm{F}$ stretching. Moreover, they also showed the stretching peaks of the sulfone groups and phenyl rings $(\mathrm{Ar}-\mathrm{H}$ and $\mathrm{C}-\mathrm{C})$ at about 1320, 3061, 1616, and $1509 \mathrm{~cm}^{-1}$. Representative FTIR and ${ }^{1} \mathrm{H}$ NMR spectra of PI 5a are shown in Fig. $1 \mathrm{~b}$ and 5, respectively. The assignments of each proton designated in the ${ }^{1} \mathrm{H}$ NMR spectrum are in complete agreement with the proposed polymer

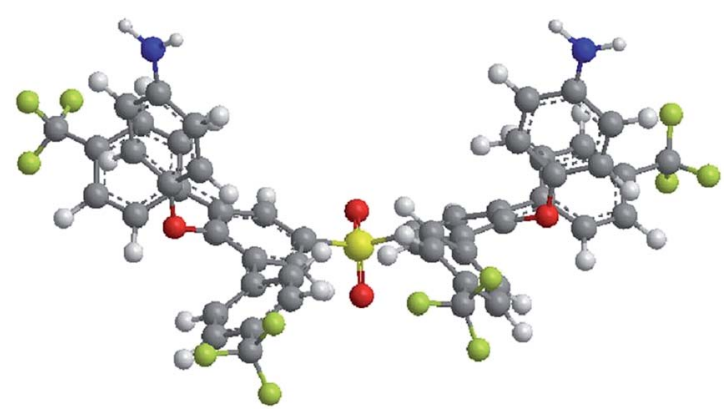

Fig. 4 Minimum energy models of diamine 3, simulated by semiempirical computations using Cambridge Software. 

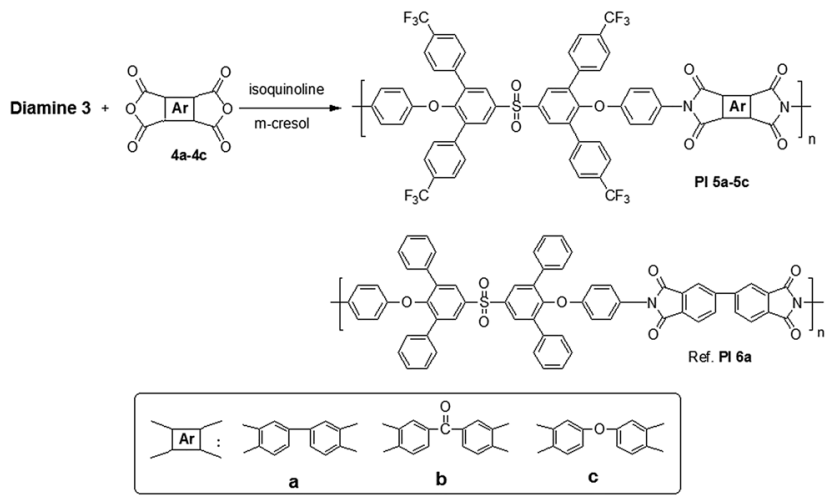

Scheme 2 Synthesis of polyimides.

Table 1 Inherent viscosities ${ }^{a}$ and GPC molecular weights of the PIs

\begin{tabular}{llcll}
\hline & \multicolumn{4}{c}{ GPC data } \\
\cline { 3 - 5 } Polymers & $\eta_{\text {inh }}\left(\mathrm{dL} \mathrm{g}^{-1}\right)$ & $M_{\mathrm{n}} \times 10^{4}$ & $M_{\mathrm{w}} \times 10^{4}$ & PDI \\
\hline 5a & 0.96 & 12.67 & 19.64 & 1.55 \\
$5 \mathrm{~b}$ & 0.79 & 8.65 & 14.18 & 1.64 \\
$5 \mathrm{c}$ & 0.83 & 10.38 & 17.54 & 1.69
\end{tabular}

${ }^{a}$ Measured at the concentration of $0.5 \mathrm{~g} \mathrm{dL}^{-1}$ in NMP at $25{ }^{\circ} \mathrm{C}$.

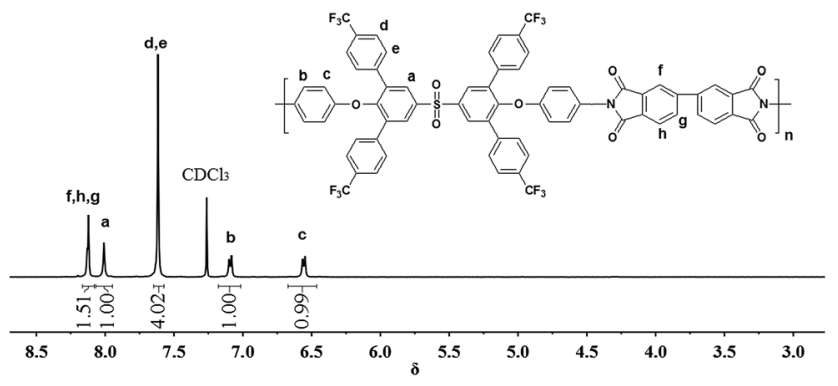

Fig. $5{ }^{1} \mathrm{H}$ NMR spectrum of PI $5 a$.

structures. Herein, the sharp peaks at $3.32 \mathrm{ppm}$ corresponding to the amine protons in the ${ }^{1} \mathrm{H}$ NMR spectrum of diamine 3 (Fig. 2) completely disappeared, and new peaks appeared at 8.12-8.14 ppm, which corresponded to the protons in the dianhydride units. All the results indicated complete imidization between the diamine and dianhydrides.

\section{Solubility and mechanical properties}

Aromatic PIs generally show rather poor solubility upon full imidation because of their highly rigid macromolecular chains and crystallinity. Therefore, most PI films are prepared from poly(amic acid) followed by imidation at high temperature of curing. ${ }^{1,9}$ Unlike these polymers, the obtained PIs 5a-c had high solubility in most tested solvents and the maximum solubility could reach $20 \mathrm{wt} \%$ in $\mathrm{NMP}, \mathrm{CHCl}_{3}$, and THF at room temperature (Table 2). The obtained PIs 5a-c had excellent solubility in NMP, DMAc, DMF, m-cresol, $\mathrm{CHCl}_{3}$, and $\mathrm{CH}_{2} \mathrm{Cl}_{2}$ at room temperature (Table 2). It was surprising that PI 5a, which was prepared from the very rigid dianhydride BPDA, showed a maximum solubility of even up to $20 \mathrm{wt} \%$ in $\mathrm{NMP}, \mathrm{CHCl}_{3}$, and THF. Compared to the analogous PI 6a containing only four phenyl groups in the repeating units, PI 5a exhibited higher solubility due to the incorporation of trifluoromethyl groups. As was expected, PIs 5a-c also displayed improved solubility compared to some fluorinated polyimides derived from the trifluoromethyl-substituted bis(ether amine)s and corresponding dianhydrides, especially in some low-boiling-point solvents. ${ }^{17-20}$ From the view of preparing films or coatings at a relatively low processing temperature, good solubility in lowboiling-point solvents is a critical requirement for applications in advanced microelectronics manufacturing. High solubility was mainly attributed to the structural modification through the incorporation of multi-bulky trifluoromethylphenyl groups in the side chain, which rendered the polymer noncoplanar and also reduced the inter-chain interactions.

Due to the excellent solubility and high-molecular weight, PI $5 \mathrm{a}-\mathrm{c}$ could be easily processed into good quality and free standing films. The films were subjected to tensile tests, and the mechanical properties of the polyimides, including the tensile strength, tensile modulus as well as elongation at break, are presented in Table 3. They exhibited good mechanical properties with a tensile strength of 82-91 $\mathrm{MPa}$, tensile modulus of 2.3-3.2 GPa, and elongation at break of 4.3-9.0\%. Although the incorporation of multi-bulky trifluoromethylphenyl groups in PIs 5a-c leads to a non-coplanar structure in the macromolecular chain, they still show equivalent mechanical properties compared to some trifluoromethyl-substituted PIs derived from the corresponding dianhydrides. ${ }^{17-20}$ The results indicated that PIs $5 \mathrm{a}-\mathrm{c}$ were tough enough for potential use in applications. The tensile modulus of the polyimides followed the order PI 5a $>$ PI $5 b>$ PI 5c, which mainly originated from different rigidities of the dianhydride units in the polymer structures. PI $5 \mathrm{~b}$ exhibited slight decrease in its tensile strength and elongation at break compared to PI $5 \mathrm{a}$ and $5 \mathrm{~b}$, which were mainly due to its lower molecular weight.

\section{Thermal properties}

The thermal properties of the polymer films are important for their application in microelectronics and optoelectronics. The thermal properties of PIs $5 \mathrm{a}-\mathrm{c}$ were determined using TGA and DSC analysis, and some characteristic data are listed in Table 4. PIs 5a-c exhibited high thermal stability with insignificant weight loss up to a temperature of approximately $550{ }^{\circ} \mathrm{C}$ under a nitrogen atmosphere. The $5 \%$ weight loss temperatures $\left(T_{\mathrm{d} 5}\right)$ under nitrogen and air atmospheres remained in the range of 551-561 ${ }^{\circ} \mathrm{C}$ and $515-520{ }^{\circ} \mathrm{C}$, respectively. The TGA results showed that the thermal stability of these polyimides was comparable to that of other trifluoromethyl-substituted PIs derived from the corresponding dianhydrides. ${ }^{17-20}$ The representative TGA curves of PI 5a are shown in Fig. 6 . The amount of carbonized residue (char yield) of these polymers under a nitrogen atmosphere was more than $55 \%$ at $800{ }^{\circ} \mathrm{C}$. The high char yields can be ascribed to the high aromatic content of the 
Table 2 Solubility behavior of the polymers ${ }^{a}$

\begin{tabular}{|c|c|c|c|c|c|c|c|c|c|}
\hline Polymers & NMP & DMAc & DMF & DMSO & $\mathrm{CHCl}_{3}$ & $\mathrm{CH}_{2} \mathrm{Cl}_{2}$ & THF & Acetone & Ethanol \\
\hline $5 a$ & 0 & ++ & ++ & + & 0 & ++ & 0 & - & - \\
\hline $5 b$ & 0 & 0 & 0 & ++ & 0 & 0 & 0 & - & - \\
\hline $6 a^{b}$ & ++ & + & + & + & ++ & + & ++ & - & - \\
\hline
\end{tabular}

${ }^{a} \bigcirc, 200 \mathrm{mg}$ sample dissolved in $1 \mathrm{~mL}$ solvent $(20 \mathrm{wt} \%) ;++$, soluble at $10 \mathrm{wt} \% ;+$, soluble at $5 \mathrm{wt} \%$; S, swelling; -, insoluble. ${ }^{b}$ The analogous PI $6 \mathrm{a}$ was prepared from 2,2'-bis[3,5-diphenyl-4-(4-aminophenoxy)phenyl]sulfone with BPDA via a one-step high-temperature polycondensation procedure in our laboratory.

Table 3 Mechanical properties of the PI films

\begin{tabular}{llll}
\hline Polymers & $\begin{array}{l}\text { Tensile strength } \\
(\mathrm{MPa})\end{array}$ & $\begin{array}{l}\text { Elongation at } \\
\text { break }(\%)\end{array}$ & $\begin{array}{l}\text { Tensile modulus } \\
(\mathrm{GPa})\end{array}$ \\
\hline 5a & 91 & 8.6 & 3.2 \\
$5 \mathrm{~b}$ & 82 & 4.3 & 2.6 \\
$5 \mathrm{~d}$ & 86 & 9.0 & 2.3
\end{tabular}

Table 4 Thermal properties of Pls $5 a-c$

\begin{tabular}{lllll}
\hline & & \multicolumn{2}{c}{$T_{\mathrm{d} 5}{ }^{b}\left({ }^{\circ} \mathrm{C}\right)$} & \\
\cline { 3 - 4 } Polymers & $T_{\mathrm{g}}{ }^{a}\left({ }^{\circ} \mathrm{C}\right)$ & In $\mathrm{N}_{2}$ & In air & Char yield $^{c}(\%)$ \\
\hline $5 \mathrm{a}$ & 281 & 561 & 520 & 56 \\
$5 \mathrm{~b}$ & 265 & 551 & 515 & 58 \\
$5 \mathrm{c}$ & 259 & 554 & 517 & 57
\end{tabular}

${ }^{a}$ Measured by DSC at the heating rate of $20^{\circ} \mathrm{C} \min ^{-1} \cdot{ }^{b} 5 \%$ weight loss temperature in TGA at $20{ }^{\circ} \mathrm{C} \mathrm{min}^{-1}$ heating rate. ${ }^{c}$ Residual weight retention at $800{ }^{\circ} \mathrm{C}$.

polymers. Evidently, PIs $5 \mathrm{a}-\mathrm{c}$ showed about $50-100{ }^{\circ} \mathrm{C}$ of $T_{\mathrm{d} 5}$ increment compared to structural polyimides with multi-bulky alkyl groups. ${ }^{9-12}$

The glass transition temperatures $T_{\mathrm{g}}$ of PIs $5 \mathrm{a}-\mathrm{c}$ were measured from DSC, and the values were in the range of 259$281{ }^{\circ} \mathrm{C}$ (Fig. 7). Generally, $T_{\mathrm{g}}$ is correlated with the stiffness and conformation of the polymer chain. The highest $T_{\mathrm{g}}$ value was

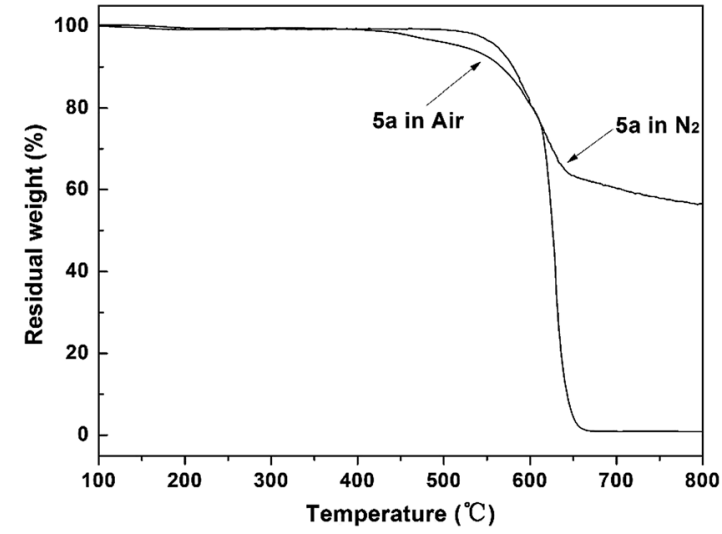

Fig. 6 TGA curves of PI $5 \mathrm{a}$ at the heating rate of $20^{\circ} \mathrm{C} \mathrm{min}^{-1}$. obtained for PI 5a and it was attributed to the rigidity of the biphenyl moiety, whereas the lowest $T_{\mathrm{g}}$ value was obtained for PI 5c and this may have been because of the presence of flexible ether linkages. Moreover, compared to other trifluoromethylsubstituted PIs, ${ }^{17-20}$ the $T_{\mathrm{g}}$ values of PIs $5 \mathrm{a}-\mathrm{c}$ were slightly lower because of the internal plasticization effect of the multibulky pendant groups. A large window between the glass transition temperature and the polymer degradation temperature also provides an opportunity for these polyimides to be meltprocessed or compression molded.

\section{Optical transparency, dielectric constants, and water absorption}

Commercial PI films often show a deep color (yellow or reddish yellow) and low optical transparency in the ultraviolet-visible region due to the strongly aromatic conjugation and intermolecular charge transfer complex. Unlike the commercial PI films, these fluorinated PI films were light in color and displayed high transparency. Fig. 8 is a comparative image of PI 5a and Kapton, and the ultraviolet-visible spectra of the obtained PIs are shown in Fig. 9. Their cut-off wavelength ( $\left.\lambda_{\text {cutoff }}\right)$ was in the range of $327-343 \mathrm{~nm}$, and the transparency at $450 \mathrm{~nm}\left(T_{450}\right)$ was higher than $80 \%$ (Table 5). PI 5a revealed a better optical transparency than the analogous PI 6a containing only four phenyl groups. Furthermore, PI 5a-c films exhibited lower $\lambda_{\text {cutoff }}$ (20-50 $\mathrm{nm}$ decrease) and better optical transparency compared to other fluorinated PIs derived from the corresponding dianhydrides. ${ }^{17-20}$ The improved optical properties were mainly

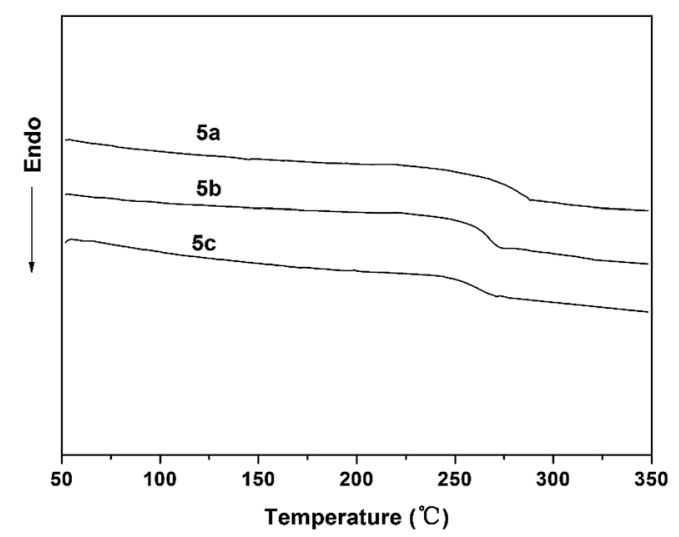

Fig. 7 DSC traces of PIs $5 \mathrm{a}-\mathrm{c}$ at the heating rate of $20^{\circ} \mathrm{C} \mathrm{min}^{-1}$. 

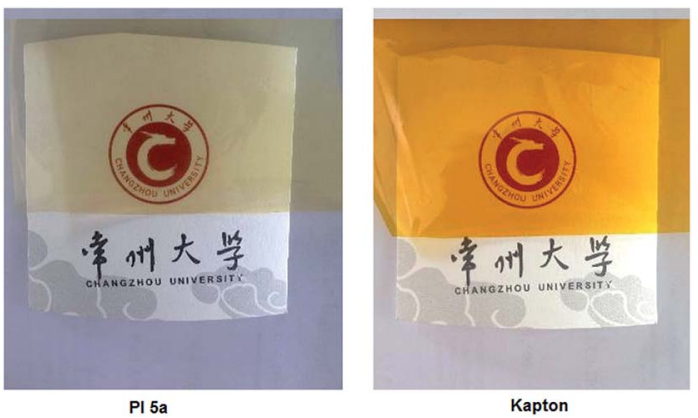

Fig. 8 A comparative image of PI 5a and Kapton.

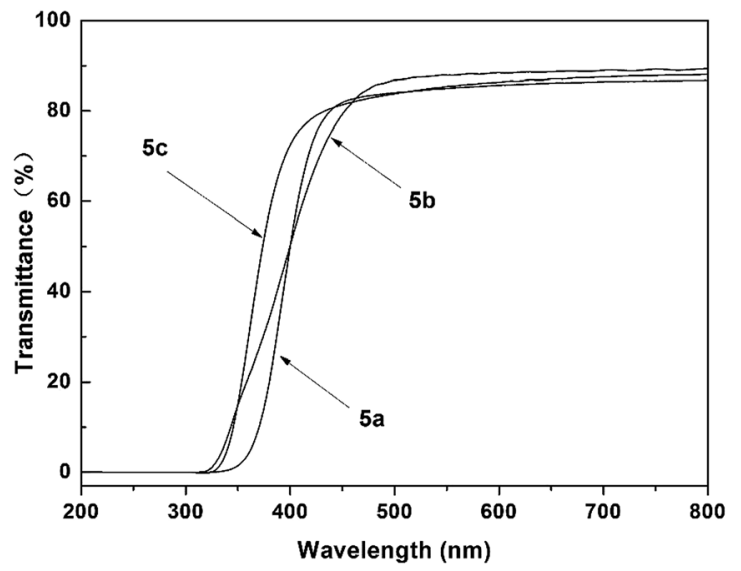

Fig. 9 UV-vis spectra of the PI $5 a-c$ films.

Table 5 Optical transparency, dielectric constants, and water absorption of the PI films

\begin{tabular}{|c|c|c|c|c|c|}
\hline \multirow[b]{2}{*}{ Polymers } & \multicolumn{2}{|c|}{ Optical properties } & \multicolumn{2}{|c|}{$\begin{array}{l}\text { Dielectric } \\
\text { constants }\end{array}$} & \multirow{2}{*}{$\begin{array}{l}\text { Water } \\
\text { absorption (\%) }\end{array}$} \\
\hline & $\lambda_{\text {cutoff }}(\mathrm{nm})$ & $T_{450}(\%)$ & $1 \mathrm{kHz}$ & $1 \mathrm{MHz}$ & \\
\hline $5 \mathrm{a}$ & 343 & 82 & 2.80 & 2.69 & 0.59 \\
\hline $5 b$ & 327 & 80 & 2.97 & 2.85 & 0.68 \\
\hline $5 \mathrm{c}$ & 329 & 81 & 2.88 & 2.77 & 0.65 \\
\hline $6 \mathrm{~b}$ & 357 & 78 & 3.17 & 3.05 & 0.98 \\
\hline Kapton & - & - & 3.54 & 3.48 & 2.1 \\
\hline
\end{tabular}

attributed to the structural modification of the polymer main chain. The incorporation of high non-coplanar diamine units with bulky multi-pendant groups could effectively reduce the aromatic conjugation and intermolecular charge transfer complex along the polymer backbone.

Dielectric properties of the polymer films are vital to their application in microelectronics. Fig. 10 depicts the dielectric constant as a function of frequency, ranging from $1 \mathrm{kHz}$ to 1 $\mathrm{MHz}$ at room temperature. PIs $5 \mathrm{a}-\mathrm{c}$ revealed low dielectric constants and the values were in the range of $2.80-2.97$ at $1 \mathrm{kHz}$ and in the range of 2.69-2.85 at $1 \mathrm{MHz}$, which were much lower than that of commercial Kapton film under the same testing condition (Table 5). Moreover, the dielectric constants of PIs 5a-

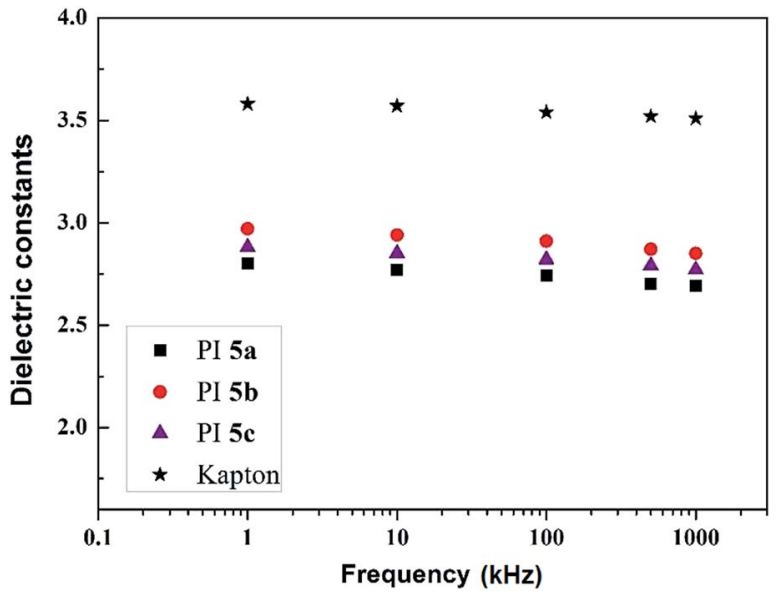

Fig. 10 Dielectric constant of Pls $5 \mathrm{a}-\mathrm{c}$ depending on electric frequency.

c were also lower than those of the analogous PI 6a, which did not contain four trifluoromethyl groups, and some trifluoromethyl-substituted polyimides derived from the corresponding dianhydrides. ${ }^{17-20}$ The effective reduction of the dielectric constants was mainly attributed to the introduction of multi-pendant trifluoromethylphenyl groups, which increased the free volume and loosened the polymer packing, subsequently reducing their dielectric constants. On the other hand, the strong electronegativity of fluorine results in very low polarizability of the C-F bonds, which could also decrease the dielectric constant. Low water absorption is also one of the key requirements for microelectronic materials, which ensures that the film maintains a stable dielectric performance. The water absorption of PI 5a-c films is listed in Table 5, and they are in the range of $0.59-0.68 \%$, which are much lower than those of the analogous PI 6a $(0.98 \%)$ and the standard Kapton film $(2.1 \%)$ due to the high content of the hydrophobic trifluoromethyl groups.

\section{Conclusions}

A new aromatic diamine monomer containing four pendant trifluoromethylphenyl groups was successfully synthesized from readily available reagents. A new family of fluorinated polyimides with high molecular weights was prepared from the newly synthesized diamine with various aromatic dianhydrides by a one-step chemical imidization method. The incorporation of multi-bulky pendant fluorinated groups and large noncoplanar structures brought about a great improvement in their properties. The obtained polyimides exhibited high solubility in many organic solvents and could be solution cast into flexible and strong films. They also had high thermal stability, good optical transparency, and low dielectric constants and water absorption. Compared to some trifluoromethylsubstituted polyimides, these polyimides with multi-bulky pendant groups possessed better solubility and lower dielectric constants and cut-off wavelength. As a result, these polyimides could be considered as promising processable high 
performance film materials for applications in microelectronic and optical devices. This study could provide a potential strategy for the preparation of high-performance fluorinated polyimides.

\section{Acknowledgements}

This work was supported by the Natural Science Foundation of Jiangsu Province (BK20141173), the Natural Science Foundation of the Jiangsu Higher Education Institutions (No. 15KJB430003), the Six Talent Peaks Project of Jiangsu Province (XCL-078), the Opening Project of State Key Laboratory for Modification of Chemical Fibers and Polymer Materials (LK1420 and LK1520), and a Project funded by the Priority Academic Program Development of Jiangsu Higher Education Institutions.

\section{Notes and references}

1 M. X. Ding, Prog. Polym. Sci., 2007, 32, 623.

2 Z. H. Yang, Y. Chen and Q. H. Wang, Polymer, 2016, 88, 19.

3 J. Zhao, L. Peng, Y. L. Zhu, Y. J. Song, L. J. Wang and Y. Z. Shen, Polymer, 2016, 91, 118.

4 N. Mushtaq, G. F. Chen, L. R. Sidra, Y. Liu and X. Z. Fang, Polym. Chem., 2016, 7, 7427.

5 J. H. Wu, W. C. Chen and G. S. Liou, Polym. Chem., 2016, 7, 1569.

6 T. Maegawa, O. Miyashita, Y. Irie, H. Imoto and K. Naka, RSC Adv., 2016, 6, 31751.

7 X. W. Peng, W. H. Xu, L. L. Chen, Y. C. Ding, T. R. Xiong, S. L. Chen and H. Q. Hou, React. Funct. Polym., 2016, 106, 93. 8 G. Maier, Prog. Polym. Sci., 2001, 26, 3.

9 Y. T. Chern, J. Y. Tsai and J. J. Wang, J. Polym. Sci., Part A: Polym. Chem., 2009, 47, 2443.
10 C. Y. Wang, X. Y. Zhao, G. Li and J. M. Jiang, Polym. Degrad. Stab., 2009, 94, 1526.

11 C. H. Lin, S. L. Chang and P. W. Cheng, J. Polym. Sci., Part A: Polym. Chem., 2011, 49, 1331.

12 G. L. Yang, R. Zhang, H. H. Huang, L. X. Liu, L. Wang and Y. M. Chen, RSC Adv., 2015, 5, 67574.

13 S. A. Sydlik, Z. Chen and T. M. Swager, Macromolecules, 2011, 44, 976.

14 Y. Rogan, L. Starannikova, V. Ryzhikh, Y. Yampolskii, P. Bernardo, F. Bazzarelli, J. C. Jansen and N. B. McKeown, Polym. Chem., 2013, 4, 3813.

15 W. X. Chen, Z. X. Zhou, T. T. Yang, R. X. Bei, Y. Zhang, S. W. Liu, Z. Chi, X. D. Chen and J. R. Xu, React. Funct. Polym., 2016, 108, 71.

16 M. G. Dhara and S. Banerjee, Prog. Polym. Sci., 2010, 35, 1022.

17 C. P. Yang and Y. Y. Su, J. Polym. Sci., Part A: Polym. Chem., 2004, 42, 222.

18 S. H. Hsiao, C. P. Yang and S. C. Huang, J. Polym. Sci., Part A: Polym. Chem., 2004, 42, 2377.

19 C. P. Yang, Y. Y. Su and K. L. Wu, J. Polym. Sci. Part A: Polym. Chem., 2004, 42, 5424.

20 S. H. Hsiao, W. J. Guo, C. L. Chung and W. T. Chen, Eur. Polym. J., 2010, 46, 1878.

21 Y. Liu, Y. Xing, Y. H. Zhang, S. W. Guan, H. B. Zhang, Y. Wang, Y. P. Wang and Z. H. Jiang, J. Polym. Sci., Part A: Polym. Chem., 2010, 48, 3281.

22 Y. Li, H. Xu, X. Tao, K. J. Qian, S. Fu and Y. Z. Shen, J. Mater. Chem, 2011, 21, 1810-1821.

23 H. Y. Yao, Y. H. Zhang, K. Y. You, Y. Liu, Y. Song, S. Y. Liu and S. W. Guan, React. Funct. Polym., 2014, 82, 58.

24 E. Cakmakci, A. Gungora and A. C. Goren, J. Fluorine Chem., 2016, 186, 66.

25 C. Y. Wang, D. W. Shin, S. Y. Lee, N. R. Kang, Y. M. Lee and D. M. Guiver, J. Membr. Sci., 2012, 405-406, 68. 